\title{
Vasopressin Mediates the Response of the Combined Dexamethasone/CRH Test in Hyper-anxious Rats: Implications for Pathogenesis of Affective Disorders
}

Martin E. Keck, M.D., Alexandra Wigger, Ph.D., Tobias Welt, B.Sc., Marianne B. Müller, M.D., Angela Gesing, Ph.D., Johannes M.H.M. Reul, Ph.D., Florian Holsboer, M.D., Ph.D., Rainer Landgraf, Ph.D., and Inga D. Neumann, Ph.D.

To investigate the neuroendocrine alterations linked to inborn emotionality in two Wistar rat lines selectively bred for either high (HAB) or low (LAB) anxiety-related behavior, we administered the combined dexamethasone $(D E X) /$ corticotropin-releasing hormone $(C R H)$ test. DEX (12:00 M. (noon); $30 \mu \mathrm{g} / \mathrm{kg}$ ) resulted in a significantly less efficient suppression of the diurnal increase in the circulating corticotropin (ACTH) levels in the male $H A B$ rats than in the male $L A B$ rats. In addition, plasma $A C T H$ and corticosterone responses to subsequent $C R H$ (7:30 P.M.; $50 \mathrm{ng} / \mathrm{kg}$ ) were significantly higher in male HAB rats. The rise in ACTH after $C R H$ in the DEX-pretreated male HAB rats points toward an enhanced activity and involvement of endogenous vasopressin synthesized in the hypothalamic paraventricular nucleus (PVN) and acting at pituitary corticotrope cells. We tested this hypothesis by in situ hybridization and in vivo microdialysis, and found an increase in both basal synthesis and release of vasopressin within the PVN of the male HAB rats. As expected, pretreatment with a selective vasopressin type 1 receptor antagonist abolished the $C R H$-stimulated increase in ACTH secretion in the DEX-pretreated male HAB rats. The results indicate that vasopressin-mediated effects are critically involved in the profound disturbance of the hypothalamic-pituitary-adrenocortical system in male $H A B$ rats, thus revealing striking parallels to the neuroendocrine situation in human depression.

[Neuropsychopharmacology 26:94-105, 2002] (C) 2001 American College of Neuropsychopharmacology. Published by Elsevier Science Inc.
KEY WORDS: ACTH; Anxiety; Corticotropin-releasing hormone; Depression; HAB; Paraventricular nucleus

From the Max Planck Institute of Psychiatry, Kraepelinstr. 2-10, D-80804 Munich, Germany

Address correspondence to: Dr. Martin E. Keck, Max Planck Institute of Psychiatry, Kraepelinstr. 2-10, D-80804, Munich, Germany, Tel.: +4989-30622-314, Fax: +49-89-30622-569, E-mail: keck@mpipsykl.mpg.de

Address correspondence to: Dr. Johannes M.H.M. Ruels's present address is Institute of Zoology, University of Regensburg, D-93053 Regensburg, Germany.

Received February 16, 2001; revised July 25, 2001; accepted August 8, 2001.

Online publication: 8/8/01 at www.acnp.org/citations/Npp 080801162
Neuroendocrine studies provide strong indications that hyperactivity of central corticotropin-releasing hormone (CRH) circuits, resulting in a characteristic dysregulation of the hypothalamic-pituitary-adrenocortical (HPA) system, plays a causal role in the symptomatology of affective and anxiety disorders (review: Keck and Holsboer 2001). The effects of CRH are modulated by vasopressin $(\mathrm{AVP})$, which, after prolonged stress and in senescence, is increasingly coexpressed and secreted from hypothalamic CRH neurons in both humans and rodents (Antoni 1993; Tilders et al. 1993; Hatzinger et al. 2000; Keck et al. 2000). Similarly, increased numbers of CRH neurons that 
coexpress AVP mRNA have been found in the hypothalamus of depressed patients (Raadsheer et al. 1993; Purba et al. 1996). The excessive release of CRH and AVP into hypophysial portal blood is thought to increase the secretion of corticotropin (ACTH) from pituitary corticotrope cells, and this in turn to increase the release of corticosteroids from the adrenal gland. In this context, a variety of changes in HPA system regulation have been demonstrated in psychiatric disorders such as major depression, among them defective negative feedback of the HPA system, basal hypercortisolemia, inappropriate HPA suppression by the synthetic corticosteroid dexamethasone (DEX) and a paradoxical stimulation of ACTH secretion by CRH after DEX pretreatment (review: Holsboer and Barden 1996; Holsboer 2000). In depression, the combined DEX/CRH test, in which DEX-pretreated subjects receive a single dose of $\mathrm{CRH}$, has proven to be the most sensitive tool for the detection of altered HPA regulation. Depending on age and gender, up to $90 \%$ of patients with depression show this neuroendocrine phenomenon (Heuser et al. 1994). Moreover, studies using the DEX/CRH test not only agree that normalization of an initial aberrance is predictive of a favorable treatment response but also corroborate other evidence that a persistent HPA abnormality correlates with chronicity or relapse (Heuser et al. 1996; Zobel et al. 1999). Since activation of corticosteroid receptors suppresses the synthesis and release of CRH and AVP from the hypothalamic paraventricular nucleus (PVN) (de Kloet et al. 1998), these findings are consistent with the hypothesis of functionally impaired corticosteroid receptor signaling in both depressed patients (Modell et al. 1997) and healthy subjects at genetic risk for depression (Holsboer et al. 1995; Modell et al. 1998).

As the mechanisms underlying the abnormal HPA reactivity in patients with certain psychiatric disorders are not fully understood, animal models are needed to further investigate the hypothesized linkage between these disorders and changes in the regulation of the HPA system. After several generations of selective breeding, we could establish two Wistar rat lines differing markedly and consistently in their inborn emotionality (Liebsch et al. 1998a,b). These animals were bred for either high (HAB) or low (LAB) anxiety-related behavior on exposure to the elevated plus-maze (EPM), one of the most widely used non-conditioned tests of rodent anxiety. However, males and females of the two rat lines differ not only in their inborn anxiety as revealed by a variety of behavioral paradigms (Liebsch et al. 1998b; Neumann et al. 1998b; Henniger et al. 2000; Ohl et al. 2001), but also in their stress coping strategies in that HAB rats show markedly passive stress coping in the forced swim test (Liebsch et al. 1998b; Keck et al. 2001a). The forced swim test is considered to have predictive value for the efficacy of antidepressant treatments in humans (review: Lucki 1997). Therefore, it is the passive stress coping behavior that renders $\mathrm{HAB}$ animals a valuable model for investigating potentially antidepressant treatment strategies such as chronic paroxetine treatment (Keck, unpublished observation), transcranial magnetic stimulation (Keck et al. 2001a) and the high-affinity CRH1 receptor antagonist R121919 (Keck et al. 2001b). Interestingly, the high emotionality of HAB rats is accompanied by an increased HPA system susceptibility to external stressors (Landgraf et al. 1999). Therefore, HAB rats provide a tool to identify neuroendocrine alterations associated with inborn emotionality in an animal model that mimics several signs and symptoms prevalent in human anxiety disorders and depression.

Recently, we established the DEX/CRH test in rats and showed characteristic alterations during aging (Hatzinger et al. 1996, 2000). In the present study, we investigated ACTH and corticosterone secretory responses during the DEX/CRH test in both HAB and LAB rats. To elucidate potential gender-specific differences, we performed the test in both male and female rats. In addition, we studied basal AVP mRNA expression and basal AVP release within the PVN using in situ hybridization and in vivo microdialysis. To explore the role of endogenous AVP in mediating HPA activity, we further studied the effect of a selective AVP type 1 $\left(\mathrm{V}_{1}\right)$ receptor antagonist on ACTH and corticosterone secretion during the DEX/CRH test. Finally, we examined the maximal number of binding sites $\left(\mathrm{B}_{\max }\right)$ and relative binding affinity $\left(\mathrm{K}_{\mathrm{d}}\right)$ of brain and pituitary mineralocorticoid (MR) and glucocorticoid receptors (GR) to see whether changes in these receptors with putative subsequent defects in corticosteroid feedback might play a role in the altered regulation of HPA activity.

\section{MATERIALS AND METHODS}

\section{Animals}

The animal studies were conducted in accordance with the Guide for the Care and Use of Laboratory Animals of the Government of Bavaria and the guidelines of the $\mathrm{NIH}$. Experiments were carried out on adult male and female HAB and LAB rats (males: $\mathrm{n}=105 ; 350 \pm 18 \mathrm{~g}$ body weight; females: $\mathrm{n}=21 ; 275 \pm 14$ g body weight). At the age of 10 weeks, $4-5$ weeks prior to the experiments, outbred $\mathrm{HAB}$ and $\mathrm{LAB}$ rats were tested on the EPM according to the breeding protocol to confirm the emotional trait (Liebsch et al.1998a,b; Landgraf et al. 1999). Rats were housed in groups of six in the breeding unit of the Max Planck Institute of Psychiatry under standard laboratory conditions until surgery $(12: 12 \mathrm{~h}$ light/dark cycle with lights on at 7 A.M., $22 \pm 1^{\circ} \mathrm{C}, 60 \%$ humidity, pelleted food and water ad libitum). After surgery the rats were housed singly in polycarbonate cages $(23 \times 39 \times 36 \mathrm{~cm})$ until testing and handled daily to reduce nonspecific stress during the experiments. 


\section{Surgery}

Surgery was performed under halothane anesthesia using aseptic procedures.

Jugular venous catheter: Five days before the experiment, the jugular vein was chronically catheterized for subsequent blood sampling as described previously (Neumann et al. 1998a; Keck et al. 2000). The catheter was exteriorized at the neck of the animal and filled with sterile saline containing gentamicin (30,000 IU/rat; Centravet, Bad Bentheim, Germany); $0.2 \mathrm{ml}$ was infused into the animal.

Microdialysis: Three days before the experiment, the U-shaped microdialysis probes (dialysis membrane: molecular cutoff of $18 \mathrm{kDa}$; Hemophan ${ }^{\mathrm{TM}}$, Gambro Dialysatoren, Hechingen, Germany) were stereotaxically implanted according to the atlas of Paxinos and Watson (1986) with their tips aimed at the right PVN $(1.5 \mathrm{~mm}$ caudal to bregma, $1.8 \mathrm{~mm}$ lateral to midline, $8.9 \mathrm{~mm}$ beneath the surface of the skull, angle of $10^{\circ}$ to avoid sagittal sinus damage). The probe was secured with dental cement to two stainless steel screws inserted into the skull.

\section{DEX/CRH Test in Male and Female HAB Rats and LAB Rats}

On the day of the experiment animals were weighed at 7 A.M. Male (HAB: $\mathrm{n}=13$, LAB: $\mathrm{n}=11$ ) and female (HAB: $n=10, L A B: n=11)$ animals were investigated in separate experiments, with the females being in proestrus or estrus of their estrous cycle as determined by vaginal smears taken at 7 A.M. on the day of the experiment. The DEX/CRH test was performed as previously described (Hatzinger et al. 1996). In brief, at 8 A.M. the jugular venous catheter was connected via $50-\mathrm{cm}$ PE-50 tubing to a plastic syringe filled with sterile heparinized saline (30 IU/ml; Ratiopharm, Ulm, Germany). Thereafter, the rats remained undisturbed. DEX $(30 \mu \mathrm{g} / \mathrm{kg}$, dissolved as phosphate in $0.9 \%$ saline; $0.5 \mathrm{ml} / \mathrm{kg}$; Merck, Darmstadt, Germany) was administered intravenously (i.v.) at $12 \mathrm{M}$. (noon), during the diurnal trough of the rats' HPA system. To monitor the effects of DEX treatment on basal plasma concentrations of ACTH and corticosterone during the diurnal acrophase, four 0.2-ml blood samples were collected at 6:00, 6:30, 7:00 and 7:30 P.M. At 7:31 P.M., CRH (50 ng/kg, 0.5 ml/kg i.v.; Ferring, Kiel, Germany) was injected. To assess the CRH-stimulated ACTH and corticosterone secretion, further blood samples were taken at 7:40, 8:00, 8:20, and 8:40 P.M.

\section{DEX/CRH Test in Vehicle- or $\mathrm{V}_{1}$ Receptor Antagonist-Treated Male HAB Rats}

The DEX/CRH test was performed in male HAB rats as described above. At 7:15 P.M., either vehicle $(0.9 \%$ saline, $0.5 \mathrm{ml} / \mathrm{kg} ; \mathrm{n}=19)$ or the $\mathrm{V}_{1 \mathrm{a} / \mathrm{b}}$ receptor antagonist $\mathrm{dP}\left[\mathrm{Tyr}(\mathrm{Me})_{2}\right] \mathrm{AVP}(10 \mu \mathrm{g} / \mathrm{kg}$ dissolved in $0.9 \%$ sterile saline, $0.5 \mathrm{ml} / \mathrm{kg}$; Dr. M. Manning, Toledo, $\mathrm{OH}$, USA; $\mathrm{n}=$ 13) was injected i.v. At 7:31 P.M., CRH ( $50 \mathrm{ng} / \mathrm{kg}, 0.5$ $\mathrm{ml} / \mathrm{kg}$ ) was injected. To assess the CRH-stimulated ACTH and corticosterone concentrations, further blood samples were taken at 7:40, 8:00, 8:20, and 8:40 P.M.

\section{Basal Intra-PVN Release of AVP in Male HAB Rats and LAB Rats}

Experiments were performed between 7 A.M. and 12 noon. Three days after surgery microdialysis $(3.3 \mu \mathrm{l} /$ min; Ringer solution, $\mathrm{pH}$ 7.4) was performed in the right PVN (HAB: $\mathrm{n}=6$, LAB: $\mathrm{n}=8$ ) as described previously (Wotjak et al. 1996b; Keck et al. 2000). After perfusion without sampling for $3 \mathrm{~h}$, two consecutive 30-min dialysates were collected and immediately stored on dry ice.

\section{Postmortem Analysis and Histology}

Animals were killed with an overdose of halothane at the end of the experiments. Brains were removed, frozen in prechilled n-methylbutane on dry ice and stored at $-80^{\circ} \mathrm{C}$. For histological verification of the placement of the microdialysis probes, $25 \mu \mathrm{m}$ coronal cryostat sections were stained with cresyl violet.

\section{Treatment of Blood Samples and Radioimmunoassays}

Blood samples were collected in prechilled tubes containing EDTA and a protease inhibitor $(10 \mu l$ aprotinin, Trasylol $^{\mathrm{TM}}$, Bayer, Germany) and centrifuged (5 min, $\left.4000 \mathrm{rpm}, 4^{\circ} \mathrm{C}\right)$. Plasma samples were stored at $-20^{\circ} \mathrm{C}$ until measurement. Plasma ACTH $(50 \mu \mathrm{l})$ and corticosterone $(10 \mu \mathrm{l})$ levels were measured using commercially available kits (Biochem, Freiburg, Germany) according to the respective protocols (sensitivity: ACTH: $<1.0 \mathrm{pg} / \mathrm{ml}$; corticosterone: $<2.0 \mathrm{ng} / \mathrm{ml})$. The intra- and interassay coefficients of variation were $7 \%$ and $10 \%$, respectively. AVP content was measured in lyophilized dialysates by a highly sensitive and selective radioimmuno-assay (detection limit: $0.1 \mathrm{pg} / \mathrm{sample}$; cross-reactivity of the antisera with other related peptides, including oxytocin, was $<0.7 \%$; for a detailed description see Landgraf et al. 1995).

\section{In situ Hybridization Histochemistry}

In situ hybridization histochemistry was performed essentially as previously described (Hatzinger et al. 2000) in male HAB $(n=5)$ and LAB $(n=5)$ rats. Briefly, consecutive frozen cryostat sections of the rat hypothalamus $(14 \mu \mathrm{m})$ were alternately mounted on polyL-lysine-coated slides for subsequent hybridization of AVP mRNA. Sections were stored at $-20^{\circ} \mathrm{C}$ until use. The following oligonucleotide DNA probe was used for 
in situ hybridization: AVP (48-mer): 5'-GCA GAA GGC CCC GGC CGG CCC GTC CAG CTG CGT GGC GTT GCT CCG GTC-3' (directed against the last 16 amino acids of the glycoprotein that are not shared with oxytocin; Ivell and Richter 1984). The specificity of this oligonucleotide has been described in detail elsewhere (Villar et al. 1994).

All sections were run in the same experiment under identical conditions. Briefly, the synthesized oligonucleotides were labeled at the $3^{\prime}$ end with $\alpha-\left[{ }^{35} \mathrm{~S}\right] \mathrm{dATP}$ (NEN DuPont) using terminal dexoynucleotidyl transferase (Boehringer, Mannheim, Germany). Radiolabeled probe $\left(10^{6} \mathrm{cpm} / 200 \mu \mathrm{l} / \mathrm{slide}\right)$ was diluted into hybridization buffer consisting of $1 \times$ Denhardt's solution, $0.25 \mathrm{mg} / \mathrm{ml}$ yeast tRNA (Sigma, Deisenhofen, Germany), $0.5 \mathrm{mg} / \mathrm{ml}$ salmon sperm DNA (Sigma, Deisenhofen, Germany), $10 \%$ dextran sulfate, $10 \mathrm{mM}$ dithiothreitol and 50\% formamide, applied to the slides and incubated for $20 \mathrm{~h}$ at $42^{\circ} \mathrm{C}$. Following hybridization, the slides were washed, 4 times for $15 \mathrm{~min}$ each, in $1 \times \operatorname{SSC}\left(55^{\circ} \mathrm{C}\right)$ dehydrated in ethanol and air-dried. Finally, the slides were dipped in Kodak NTB2 emulsion diluted 1:1 in distilled water, exposed for five weeks at $4^{\circ} \mathrm{C}$ and then developed in Kodak D19 solution. The developed slides were lightly counterstained with cresyl violet and examined using a Leica microscope with both bright- and dark-field condensers. To check for the specificity of the oligonucleotide binding, some sections were pre-incubated with a 50-fold excess of the cold oligonucleotides before the radioactively labeled probes were added. Under these conditions no signals were registered within the respective nuclei.

For evaluation of the hybridization signals, sections of the same level of the PVN were chosen according to the brain atlas of Paxinos and Watson (1986), and histological criteria (prominent part of magnocellular and parvocellular neurons, respectively). For objective evaluation, the images of at least three stions per animal were scanned by a computer-assisted image analyzer (Optimas-Bioscan) fitted with a Zeiss Axioplan microscope and a Sony CCD camera. The images were overlapped with predefined masks, which enclosed either the magnocellular or the parvocellular part of the PVN (according to Kiss 1988, Kiss et al. 1991). Levels of mRNA expression (optical density) were determined by measuring the mean gray value on inverted (in situ hybridization signal: black), automatically thresholded images in the PVN, with the left and right hemispheres being analyzed separately. The mean values for each animal and region were calculated.

\section{Immunohistochemistry}

Immunohistochemistry was performed exactly as described previously (Müller et al. 2000b). Briefly, animals ( $\mathrm{n}=4$ per breeding line) were deeply anesthetized with phenobarbital and transcardially perfused with phosphate-buffered $4 \%$ paraformaldehyde. Brains were removed from the skull, postfixed for $6 \mathrm{~h}$ in $4 \%$ paraformaldehyde and then transferred to $15 \%$ sucrose in phosphate-buffered saline (PBS; pH 7.4). Serial 30-mm coronal frozen sections were cut in a cryostat into PBS and processed as free-floating sections. For each animal, all sections spanning the region of the median eminence were analyzed to allow for exact comparison. All following steps were interposed by copious washes in PBS, and all reagents for immunohistochemistry were diluted in PBS with $1 \%$ bovine serum albumin (BSA) unless otherwise specified. After blocking of endogenous peroxidase in absolute methanol with $0.01 \%$ hydrogen peroxide for $15 \mathrm{~min}$, preincubation with $5 \%$ normal goat serum for $2 \mathrm{~h}$ was performed. The sections were then incubated with the primary antibody diluted 1:10,000 (polyclonal rabbit-anti AVP antibody (IHC 8103, Peninsula Laboratories, Belmont, California, USA) at $4^{\circ} \mathrm{C}$. The sections were then incubated with a biotinylated goatanti-rabbit secondary antibody diluted 1:300 for $45 \mathrm{~min}$ at room temperature (Vector, USA), followed by incubation with avidin-biotinylated horseradish peroxidase complex (ABC Elite universal kit, Vector) for $45 \mathrm{~min}$ at room temperature (1:300). Finally, the sections were developed in a substrate solution of $0.05 \%$ diaminobenzidine tetrahydrochloride and $0.01 \%$ hydrogen peroxide in $0.05 \mathrm{M}$ Tris- $\mathrm{HCl}, \mathrm{pH}$ 7.6, washed, mounted on glass slides, air-dried and lightly counterstained with hematoxylin. Appropriate negative controls were performed by omission of the primary antibody.

\section{Adrenalectomy, Tissue Collection and $\left[{ }^{3} \mathrm{H}\right]$-steroid Binding Assay}

In a separate set of experiments, the MR and GR concentrations were assessed by a soluble corticosteroid binding assay (Reul and de Kloet 1985; Reul et al. 1993). For the corticosteroid binding experiments, male HAB $(n=11)$ and LAB $(n=10)$ rats were bilaterally adrenalectomized (ADX; via the dorsal approach under halothane anesthesia) between 7 A.M. and noon, i.e. $24 \mathrm{~h}$ before sacrifice. ADX rats received $0.9 \% \mathrm{NaCl}$ in tap water as their drinking solution. One day after ADX, rats were quickly anesthetized with halothane and decapitated. Trunk blood was collected in pre-chilled EDTA-coated tubes and the plasma was checked for the absence of any corticosterone by radioimmunoassay. Animals with detectable levels of corticosterone were excluded. Brains were rapidly removed from the skull, the hippocampus and hypothalamus were dissected and the anterior pituitary was collected. Dissected tissues were instantaneously frozen in liquid $\mathrm{N}_{2}$ and stored at $-80^{\circ} \mathrm{C}$ until corticosteroid receptor assay as described elsewhere (Reul et al. 1993). 
Briefly, brain tissues were individually homogenized. Because of their small size, anterior pituitary tissues were pooled per group. The homogenate was centrifuged to obtain cytosol (i.e. supernatant fraction). All reagents used were analytical grade. Aliquots of cytosol were incubated with $\left[{ }^{3} \mathrm{H}\right]$-labeled steroids ( $10 \mathrm{nM} ;>90 \%$ saturation) in triplicate. Apart from these individual cytosol incubations, pooled cytosol for each group was established by mixture of equal aliquots of each individual cytosol. The pooled cytosol was required to obtain a large enough amount to conduct incubations over an extended concentration range (0.1-10 $\mathrm{nM}$ in duplicate) for saturation binding analysis and Scatchard analysis for the determination of the affinity binding constant $\left(\mathrm{K}_{\mathrm{d}}\right)$. Total binding to soluble macromolecules was determined with $\left[{ }^{3} \mathrm{H}\right]$-aldosterone (87-94 $\mathrm{Ci} / \mathrm{mmol}$, NEN DuPont, Dreieich, Germany) or with [ $\left.{ }^{3} \mathrm{H}\right]-$ DEX (85-106 Ci/mmol, Amersham, Braunschweig, Germany). For measurement of MRs, total binding was assessed by incubating cytosol with $\left[{ }^{3} \mathrm{H}\right]$-aldosterone in the presence of a 100-fold excess of the specific glucocorticoid RU 28362 (11ß,17ß-dihydroxy-6-methyl-17 -(1-propionyl)androsta-1,4,6-triene-3-one). Unlabeled RU 28362 was included to prevent $\left[{ }^{3} \mathrm{H}\right]$-aldosterone from binding to GRs, so that only binding of this $\left[{ }^{3} \mathrm{H}\right]$-ligand to MR was measured. Nonspecific binding was determined in parallel incubations containing a 1000-fold excess of corticosterone in addition to cytosol and $\left[{ }^{3} \mathrm{H}\right]$-aldosterone. Total binding for the GR was determined by incubating cytosol with $\left[{ }^{3} \mathrm{H}\right]-D E X$. Since $\left[{ }^{3} \mathrm{H}\right]-D E X$ also displays considerable affinity for MR, the fraction of $\left[{ }^{3} \mathrm{H}\right]-\mathrm{DEX}$ binding to MR was estimated by including a 100-fold excess of RU 28362 in parallel incubation tubes. Nonspecific binding was determined in parallel incubations containing a 1000-fold excess of DEX in addition to cytosol and [ $\left.{ }^{3} \mathrm{H}\right]-D E X$. Bound and free $\left[{ }^{3} \mathrm{H}\right]$-steroid were separated by Sephadex LH-20 (Pharmacia, Sweden) gel filtration, and radioactivity was measured in a liquid scintillation counter. The protein concentration was determined by the method of Lowry with BSA as the standard. The binding data were expressed as $\mathrm{fmol} / \mathrm{mg}$ protein, and nonspecific binding was subtracted from total binding to yield specific binding. This enabled direct measurement of the MR concentration; GR binding, however, was estimated by subtraction of the specific binding of $\left[{ }^{3} \mathrm{H}\right]-\mathrm{DEX}+100 \times \mathrm{RU} 28362$ from the specific binding of $\left[{ }^{3} \mathrm{H}\right]-\mathrm{DEX} .\left[{ }^{3} \mathrm{H}\right]-\mathrm{DEX}+100 \times$ RU 28362 rather than $\left[{ }^{3} \mathrm{H}\right]$-aldosterone $+100 \times$ RU 28362 binding data were used to estimate the amount of the specific $\left[{ }^{3} \mathrm{H}\right]-D E X$ binding to MR because $\left[{ }^{3} \mathrm{H}\right]-\mathrm{DEX}+100 \times$ RU 28362 binding to MRs has been found to be about 30\% less than $\left[{ }^{3} \mathrm{H}\right]$-aldosterone $+100 \times \mathrm{RU} 28362$ binding to this receptor type (Reul, unpublished observation).

\section{Statistical Analysis}

Results are reported as means \pm SEM. After CRH administration, $\mathrm{ACTH}$ and corticosterone responses were computed as the area under the concentration-time curve (AUC, arbitrary units) corrected for basal concentration (averaged plasma concentration of ACTH and corticosterone, respectively, between 6:00 and 7:30 P.M.) using trapezoidal integration. Additionally, the ratios of the AUCs for ACTH and corticosterone were calculated as a crude estimate of adrenal responsiveness to ACTH (pituitary-adrenal ratio). To analyze the in situ hybridization data, the mean gray value per region and animal was calculated. Binding data were expressed as fmol/ $\mathrm{mg}$ and in the case of the individual cytosol measurements (except for anterior pituitary) group means. Scatchard analyses were performed on the binding data from pooled cytosol and maximal binding capacity $\left(B_{\max }\right)$ and $K_{d}$ were calculated. Statistical analysis was performed with a statistical software package (GB-Stat version 6.0, Dynamic Microsystems, Silver Spring, MD, USA). Statistical significance was determined by 2-way ANOVA for repeated measures (group X time) followed by Fisher's least-significant-difference protected $t$-test, or the MannWhitney U-test (for comparisons of the number of positively labeled cells/silver grains, AVP dialysates and AUC values). Statistical significance was accepted if $p<.05$.

\section{RESULTS}

\section{DEX/CRH Test in Male HAB Rats and LAB Rats}

After DEX pretreatment, the usual elevation in basal plasma ACTH levels due to the diurnal rise in HPA system activity was abolished in the male LAB rats, whereas in the male HAB rats basal ACTH levels at 6:00, 7:00 and 7:30 P.M. were significantly higher, indicating DEX nonsuppression. The release of ACTH in response to $\mathrm{CRH}$ was significantly greater in the male $\mathrm{HAB}$ than the male LAB rats (2-way ANOVA, group $\mathrm{X}$ time: $p=.03$; Figure 1), which was also reflected by significantly higher AUC values (HAB: $2346 \pm 400$; LAB: $883 \pm 268 ; p<.05)$. Similarly, the maximal rise of the plasma corticosterone concentration after CRH stimulation was significantly greater in the HAB than in the LAB rats (group X time: $p=.0062$ ), which was also reflected by higher AUC values (HAB: $8306 \pm 1500$; LAB: $3709 \pm 458 ; p<.05)$.

The pituitary-adrenal ratio was similar in the $\mathrm{HAB}$ $(0.28 \pm 0.07)$ and LAB animals $(0.24 \pm 0.05 ; p=.94)$, indicating that the adrenal responsiveness to ACTH is not significantly different between male $\mathrm{HAB}$ and $\mathrm{LAB}$ rats.

\section{DEX/CRH Test in Female HAB Rats and LAB Rats}

After DEX pretreatment, there were no statistically significant differences in basal ACTH plasma concentrations (6:00-7:30 P.M.) between female HAB and female $\mathrm{LAB}$ rats. After $\mathrm{CRH}$ stimulation, the rise in the $\mathrm{ACTH}$ level was abolished in both groups of rats (group $X$ 

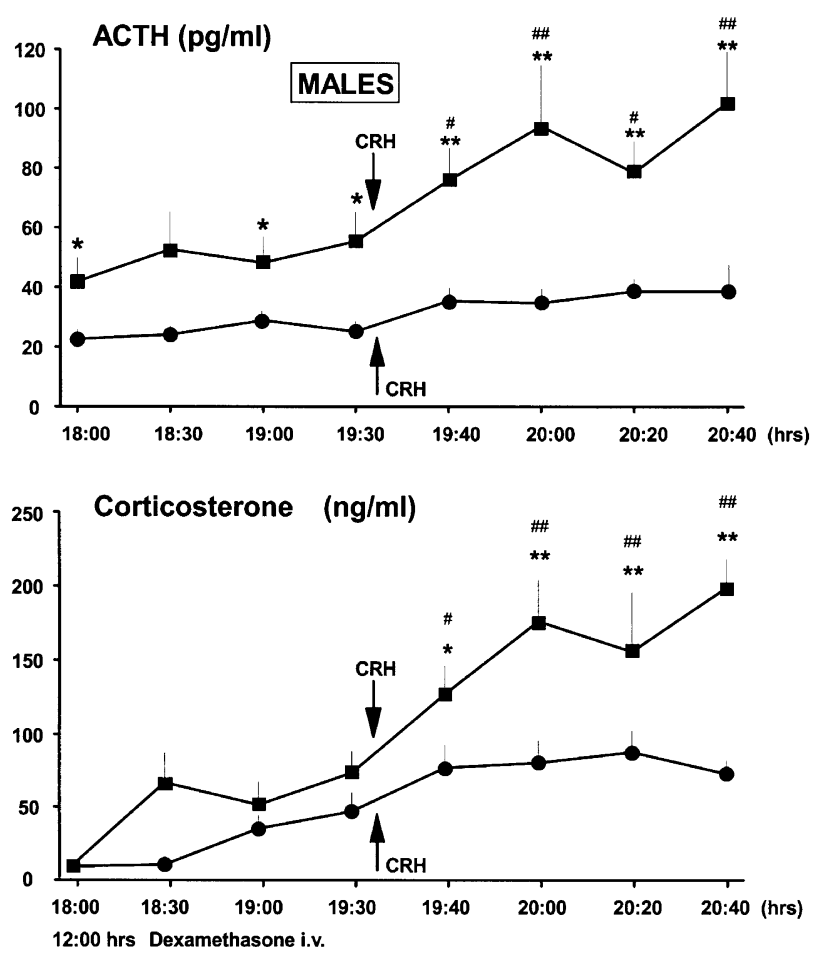

Figure 1. Plasma $\mathrm{ACTH}$ and corticosterone concentrations of male HAB (squares; $n=13$ ) and LAB (circles; $n=11$ ) rats between 6:00 and 8:40 P.M. during the combined DEX/CRH test. All rats were pretreated with DEX (30 $\mu \mathrm{g} / \mathrm{kg}$ i.v.) at 12:00 M. CRH was administered (50 ng/ kg i.v.) at $1931 \mathrm{~h}$ (arrow). Values are means \pm SEM. ${ }^{*} p<.05,{ }^{* *} p<.01$ vs. LAB. \#p $<.05, \# \# p<.01$ vs. basal.

time: $p=.28$; Figure 2), which was also reflected by similar AUC values (HAB: $236 \pm 37$; LAB: $214 \pm 53 ; p>$ .05). There were no significant differences in basal plasma corticosterone levels after DEX-pretreatment between the female $\mathrm{HAB}$ and $\mathrm{LAB}$ rats. In contrast to $\mathrm{ACTH}$ secretion, the rise in the plasma corticosterone concentration was not abolished in either group in response to CRH stimulation (factor time: $p<.0001$; Figure 2). There was no difference in corticosterone AUC values between the female $\mathrm{HAB}$ and $\mathrm{LAB}$ animals (HAB: $2916 \pm 513$; LAB: $2818 \pm 708 ; p>.05$ ).

\section{DEX/CRH Test in Male HAB Rats Treated with Vehicle or $V_{1}$ Receptor Antagonist}

After DEX pretreatment, basal ACTH and corticosterone levels between 6:30 and 7:30 P.M. did not differ between the groups of male HAB rats treated subsequently with either vehicle or the $V_{1}$ receptor antagonist (Figure 3). Administration of vehicle or the $\mathrm{V}_{1}$ receptor antagonist had no immediate effect (first 15 min) on ACTH or corticosterone secretion (Figure 3). However, antagonist administration attenuated the $\mathrm{CRH}$-stimulated increase in both ACTH and corticos-
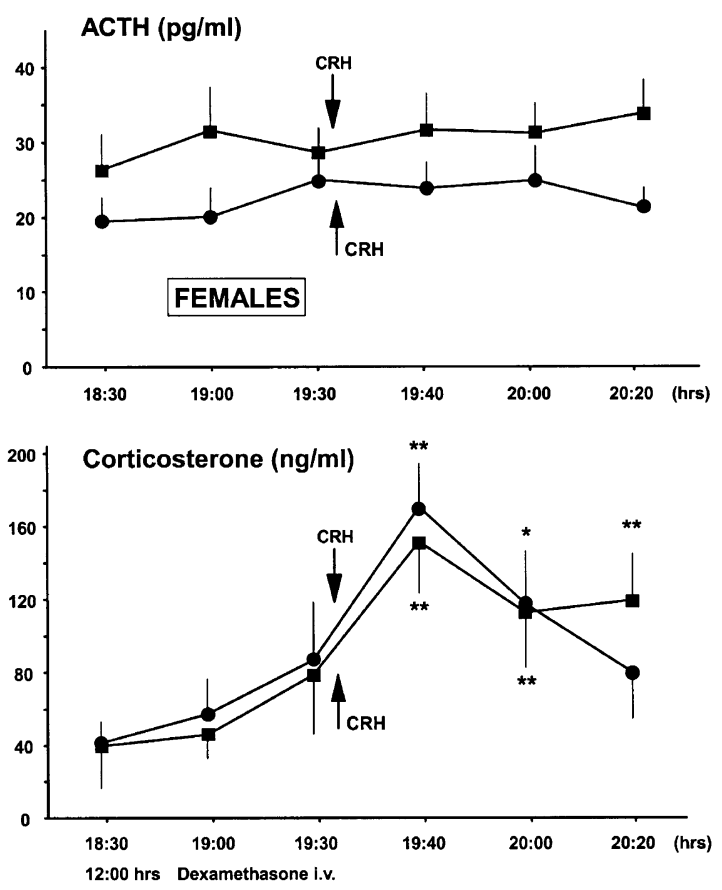

Figure 2. Plasma ACTH and corticosterone concentrations of female HAB (squares; $n=10$ ) and LAB (circles; $n=11$ ) rats between 6:30 and 8:20 P.M. during the combined DEX/ CRH test. All rats were pretreated with DEX (30 $\mu \mathrm{g} / \mathrm{kg}$ i.v.) at $1200 \mathrm{M}$. CRH was administered (50 ng/kg i.v.) at $1931 \mathrm{~h}$ (arrow). Values are means \pm SEM. There were no significant differences between groups. ${ }^{*} p<.05,{ }^{* *} p<.01 \mathrm{vs}$. basal.

terone secretion seen in the vehicle-treated $\mathrm{HAB}$ rats (time $\mathrm{X}$ treatment: $p<.0001$ and $p<.05$, respectively). This effect was also reflected by lower AUC values for both ACTH (vehicle: $3386 \pm 343 ; \mathrm{V}_{1}: 1169 \pm 214 ; p<$ $.01)$ and corticosterone (vehicle: $4675 \pm 424 ; \mathrm{V}_{1}: 2739 \pm$ 534; $p<.05)$ after treatment with antagonist.

\section{Basal Intra-PVN Release of AVP in Male HAB and LAB Rats}

The averaged AVP content of two consecutive dialysates collected from the PVN of male HAB and LAB rats was found to be significantly different $(p<.05)$, with higher basal levels in HAB rats (Figure 4).

\section{Expression of AVP mRNA within the PVN of Male HAB and LAB Rats}

Only a few scattered silver grains were detectable within the parvocellular neurons of the PVN synthesizing AVP in male HAB and LAB rats decapitated under basal conditions. In contrast, the mean gray value within the magnocellular part of the PVN was significantly higher in the male HAB rats (Figure $4 ; p<.05$ ). 

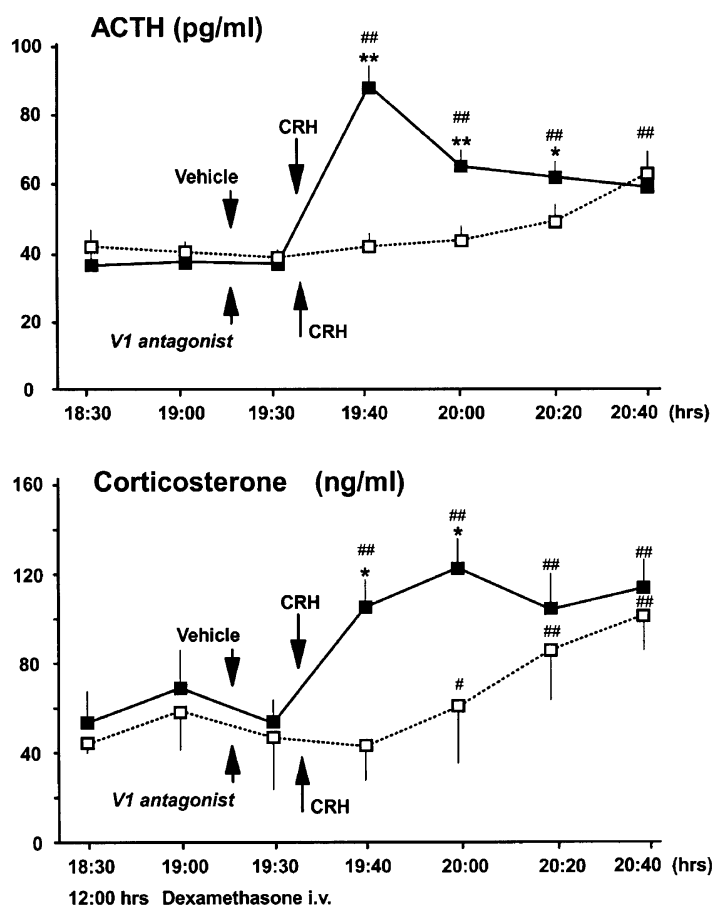

Figure 3. Plasma ACTH and corticosterone concentrations of vehicle-treated (solid lines; $n=19$ ) and $V_{1}$ receptor antagonisttreated (dashed lines; $n=13$ ) male HAB rats between $6: 30$ and 8:40 P.M. during the combined DEX/CRH test. All rats were pretreated with DEX (30 $\mu \mathrm{g} / \mathrm{kg}$ i.v.) at 12:00 M. Vehicle or $\mathrm{V}_{1}$ receptor antagonist $(10 \mu \mathrm{g} / \mathrm{kg}$ i.v.) was injected at 7:15 P.M. (arrow), i.e. $15 \mathrm{~min}$ before CRH was administered (50 $\mathrm{ng} / \mathrm{kg}$ i.v.) at 7:31 P.M. (arrow). Values are means \pm SEM. ${ }^{*} p<.05,{ }^{* *} p<$ .01 vs. corresponding values in $\mathrm{V}_{1}$ receptor antagonist-treated male HAB rats. $\# p<.05, \# p<.01$ vs. basal.

\section{Immunohistochemistry}

There were no differences in AVP-like immunoreactivity between the male $\mathrm{HAB}$ and $\mathrm{LAB}$ rats in either the external or internal zone of the median eminence (data not shown).

\section{GR and MR Binding in Hippocampus, Hypothalamus and Pituitary of Male HAB and LAB Rats}

Table 1 shows that there were no statistically significant differences between the male $\mathrm{HAB}$ and $\mathrm{LAB}$ rats in $\mathrm{B}_{\max }$ or $K_{d}$ of GR or MR in any of the brain regions studied.

\section{DISCUSSION}

The HAB and LAB rat lines, differing markedly in their inborn anxiety-related and acute stress coping behaviors (Liebsch et al. 1998a,b; Keck et al. 2001a), provide a promising tool for investigating the relationship between inborn emotionality, acute stress coping, physio-
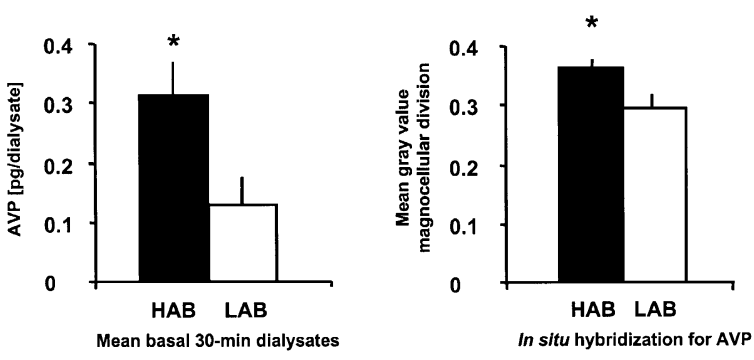

Figure 4. Left panel: AVP content of 30-min dialysates (mean of dialysates 1 and 2) collected consecutively in the PVN of freely moving male HAB $(n=6)$ and LAB $(n=8)$ rats. Right panel: Quantitative analysis of AVP mRNA in situ hybridization signals of the magnocellular division of the PVN of male HAB $(n=6)$ and LAB $(n=8)$ rats. Values are means \pm SEM. ${ }^{*} p<.05$ vs. LAB.

logical and neuroendocrine stress responses and their underlying mechanisms (Liebsch et al. 1998a). Thus, studies on aberrant patterns in these selected laboratory animals genetically predisposed to certain behavioral strategies may contribute to a better understanding of human psychopathology states. Using the combined DEX/CRH test we were able to demonstrate a profound dysregulation of the HPA system in male rats with inborn hyperanxiety. The significantly elevated basal synthesis and release of AVP within the PVN indicates that AVP is critically involved in the aberrant HPA system reactivity under these psychopathological conditions. Accordingly, administration of a selective $\mathrm{V}_{1}$ receptor antagonist abolished the increased plasma $\mathrm{ACTH}$ and corticosterone response to the CRH challenge in the DEX-pretreated male HAB animals. This is

Table 1. MR and GR Characteristics in the Hippocampus, Hypothalamus and Anterior Pituitary of Male HAB and LAB Rats

\begin{tabular}{|c|c|c|c|c|}
\hline & $\begin{array}{c}\text { MR } \\
\text { (fmol/mg) }\end{array}$ & $\begin{array}{c}\text { MR K }_{\mathrm{d}} \\
(\mathrm{nM})\end{array}$ & $\begin{array}{c}\text { GR } \\
(\mathrm{fmol} / \mathrm{mg})\end{array}$ & $\begin{array}{c}\mathrm{GR} \mathrm{K}_{\mathrm{d}} \\
\text { (nM) }\end{array}$ \\
\hline \multicolumn{5}{|c|}{ Hippocampus } \\
\hline HAB & $95 \pm 11^{a}$ & $0.26^{b}$ & $194 \pm 7^{a}$ & $1.18^{b}$ \\
\hline LAB & $107 \pm 9^{a}$ & $0.23^{b}$ & $201 \pm 7^{a}$ & $1.08^{b}$ \\
\hline \multicolumn{5}{|c|}{ Hypothalamus } \\
\hline HAB & - & - & $213 \pm 10^{a}$ & - \\
\hline LAB & - & - & $199 \pm 11^{a}$ & - \\
\hline \multicolumn{5}{|c|}{ Anterior pituitary } \\
\hline HAB & - & - & $144^{c}$ & $1.96^{d}$ \\
\hline $\mathrm{LAB}$ & - & - & $150^{c}$ & $1.97^{d}$ \\
\hline
\end{tabular}

${ }^{a}$ Receptor binding capacity measured in cytosol of tissues of individual animals at a single saturating $\left(>90 \%\right.$ of $\left.\mathrm{B}_{\max }\right)\left[{ }^{3} \mathrm{H}\right]$-ligand concentration. Rats were adrenalectomized one day before killing. Data are expressed as $\mathrm{fmol} / \mathrm{mg}$ protein (means $\pm \mathrm{SEM} ; \mathrm{n}=10-11$ ).

${ }^{b} \mathrm{~K}_{\mathrm{d}}$ (in $\mathrm{nM}$ ) was determined by saturation binding and Scatchard analysis on pooled cytosol established by mixing aliquots of the cytosol prepared from the individual tissues.

${ }^{c} \mathrm{~B}_{\max }\left(\mathrm{fmol} / \mathrm{mg}\right.$ protein) ${ }^{d} \mathrm{~K}_{\mathrm{d}}(\mathrm{nM})$ values as determined by saturation binding and Scatchard analysis on cytosol prepared per group from pooled anterior pituitary tissues. 
the first direct evidence that the activation of the vasopressinergic system accounts for the disturbance of the HPA system in male HAB rats.

\section{Aberrant Outcome of the Combined DEX/CRH Test in Male HAB Rats}

In rats, the peak in plasma ACTH and glucocorticoids is found at the onset of the normal period of wakefulness in the evening and a trough is observed $12-18 \mathrm{~h}$ later (Krieger 1979). Receptor occupancy by endogenous glucocorticoids at the pituitary, which is known to be the preferred site of DEX action (Schinkel et al. 1995; de Kloet et al. 1998; Meijer et al. 1998), is minimal during the diurnal trough. Thus, a maximal effect is achieved by administering DEX at $12 \mathrm{M}$, when the endogenous HPA system activity is minimal (Krieger 1979; Hatzinger et al. 1996).

Our finding of elevated basal ACTH levels 6-7 h after DEX pretreatment in male HAB rats, but not in male $L A B$ rats, indicates a partial failure of DEX suppression in $\mathrm{HAB}$ rats. In male $\mathrm{LAB}$ rats subsequent $\mathrm{CRH}$ stimulation failed to induce an escape of ACTH and corticosterone from DEX suppression, which supports the idea of a reciprocal interaction between exogenous and/or endogenous glucocorticoid titers and the degree of pituitary-adrenocortical activation by CRH (Rivier et al. 1982; Hatzinger et al. 1996). In contrast, as in patients suffering from major depression (Holsboer and Barden 1996), male HAB rats responded with a substantial increase in ACTH and corticosterone. Because the pituitary-adrenal ratios were indistinguishable between $\mathrm{HAB}$ and $\mathrm{LAB}$ rats, our data do not support the view that changes at the adrenal level account for the increased ACTH and corticosterone secretion after a CRH challenge. Furthermore, earlier studies showed a similar response of pituitary corticotropes to an i.v. CRH challenge in male $\mathrm{HAB}$ and $\mathrm{LAB}$ rats (Liebsch et al. 1998a; Keck et al. 2001a).

The aberrant outcome of the DEX/CRH test was gender-dependent as the female HAB rats were found to be indistinguishable from the female LAB rats when tested during the proestrus/estrus phase of their estrous cycle. Thus, in females DEX-suppression of ACTH secretion could be found in both HAB and $L A B$ rats. Subsequent $\mathrm{CRH}$ stimulation did not cause escape of ACTH secretion from DEX suppression in either $\mathrm{HAB}$ or $\mathrm{LAB}$ females. In contrast, there was a profound corticosterone response to $\mathrm{CRH}$ stimulation, which, again, was indistinguishable between HAB and LAB females. This, however, is indicative of a generally enhanced adrenal sensitivity to ACTH in female rats under these conditions. Consistent with these findings, it could also be demonstrated in human studies that gender profoundly affects DEX/CRH test outcome (Heuser et al. 1994; Zobel et al. 2001).
It has been reported that the activity of the HPA system varies with the level of sexual steroids during the estrous cycle (Viau and Meaney 1991) and during female reproduction (Lightman and Young 1989; Walker 1995; Neumann et al. 1998a,b), and that there are differences between males and females (Kitay 1961; Rivier 1999; Neumann et al. 2000). Interestingly, prenatal (Weinstock 1997) and postnatal (Wigger and Neumann 1999) stress altered HPA system responsiveness in adult male, but not female, offspring demonstrating a greater vulnerability in males than in females. However, females of the HAB and LAB breeding lines show the same differences in their emotional profile as males (Liebsch et al. 1998b; Neumann et al. 1998b). Recent results also show a hyperresponsiveness of the HPA axis of female HAB rats when exposed to the maternal defense test (Neumann and Douglas, unpublished observation), a relevant stressor for females (Neumann et al. 2001).

\section{Hyperactivity of the Intra-PVN Vasopressinergic System: Major Drive of the Aberrant Outcome of the DEX/CRH Test or Compensatory Mechanism?}

After the discovery of CRH (Vale et al. 1981) it was rapidly established that AVP potently synergizes with CRH to stimulate pituitary ACTH secretion: when CRH and AVP are co-administered, hormone output is well above the combined effects of the two neuropeptides in both humans (von Bardeleben and Holsboer 1985) and rodents (Gillies et al. 1982). AVP is mainly synthesized in the magnocellular neurons of the hypothalamic PVN and the supraoptic nucleus. In addition, CRH and AVP are (co-)localized in parvocellular neurons of the PVN (Tilders et al. 1993), representing the hypothalamic origin of the HPA system. The CRH/AVP synergism is known to be functionally relevant under conditions of long-term activation of the HPA system, such as chronic stress in rats (e.g. de Goeij et al. 1992), human and rodent aging (Lucassen et al. 1993; Hatzinger et al. 2000; Keck et al. 2000) and human depression (Holsboer 1999; Purba et al. 1996). Thus, the hypothalamic signal for ACTH secretion produced by the parvocellular CRH neurons gradually shifts from a CRH-dominated signal to a more AVP-dominated one (Tilders et al. 1993). Indeed, Purba et al. (1996) found indications of an enhanced vasopressinergic drive by showing an increased number of AVP-expressing neurons in the PVN of depressed patients. Although the findings so far are not consistent (Heuser et al. 1998), additional indirect evidence for a role of AVP in affective disorders comes from the finding that fluoxetine treatment leads to a reduction in cerebrospinal fluid concentrations of AVP in patients with major depression (de Bellis et al. 1993). In this context there is strong evidence that AVP derived 
not only from parvocellular neurons of the PVN, but also from the magnocellular neurosecretory system, contributes to HPA system activity: AVP can be released from magnocellular neurons into the portal blood system, either by en passant release while passing through the internal zone of the median eminence or via short portal vessels from the posterior pituitary (Antoni 1983; Wotjak et al. 1996a,b).

The present study provides evidence that AVP contributes to the marked dysregulation of the HPA system in the HAB rat, which may be considered a genetically prone animal model to study the neurochemical correlates of depression and anxiety. The escape of both ACTH and corticosterone from the suppressive effects of DEX could be abolished by peripheral administration of a selective $V_{1}$ receptor antagonist prior to the CRH challenge. Interestingly, both the synthesis of AVP in magnocellular neurons of the PVN and the release of AVP within the PVN were found to be increased more in $\mathrm{HAB}$ than in LAB rats, which favors hyperactivity of the magnocellular vasopressinergic system as an explanation for HPA system alterations. As an approach to study a differential activation of magnocellular and parvocellular AVP neurons in HAB and LAB rats, we used the detection of AVP-like immunoreactivity in the internal and external zone of the median eminence, which was indistinguishable in the two rat breeding lines. Therefore, increased intra-PVN release, and thus increased local synthesis of AVP in magnocellular neurons of this nucleus, might simply represent local compensatory mechanisms of the organism to counterregulate an HPA system that is hyperactive per se (Wotjak et al. 1996b). Accordingly, secretion of AVP into the blood circulation is similar in HAB and LAB rats under basal conditions (Landgraf et al. 1999), arguing against a general hyperactivity of the magnocellular AVP system in HAB rats.

As has been hypothesized for human major depressive illness, in the HAB rats the vasopressinergic hyperdrive partially overrides the inhibitory action of DEX on ACTH release by the enhanced AVP secretion, which acts synergistically to the external CRH challenge in the DEX/CRH test (review: Holsboer and Barden 1996). The elevated central (intra-PVN) release of AVP in male HAB rats shown in this study adds a new dimension to the phenomenon of AVP hyperdrive in psychopathology and deserves further investigation.

\section{Involvement of Glucocorticoid and Mineralocorticoid Receptors}

Although the mechanisms underlying the abnormal HPA reactivity to a combined DEX/CRH test in depressed patients are not fully understood, defects in the corticosteroid feedback regulation of the activity of the HPA system have been hypothesized (Modell et al. 1997, 1998; review: Holsboer 2000). This altered feed- back might be involved in adaptive changes described post mortem in the hypothalamic CRH and AVP neurons that control the pituitary-adrenocortical system (Purba et al. 1996). Thus, the HAB animals may represent a promising model for further investigation of the psychopathological significance of a dysregulated HPA system.

Recently, stress induced by social defeat has been found to prompt long-lasting changes in the regulation of the HPA system in rats, in that the ACTH response to CRH after DEX administration was significantly greater in defeated rats than in controls (Buwalda et al. 1999). These changes were reflected in temporal dynamic alterations in hippocampal, hypothalamic and pituitary GR and MR binding. In this context it is important to note that the translation of the corticosteroid signal into a cellular response comprises various steps, including receptor binding, trafficking to the nucleus and nuclear actions of ligand-activated receptors (Holsboer 2000). In the present study we did not detect any alterations in either GR or MR binding. Therefore, the pathological DEX/ $\mathrm{CRH}$ challenge outcome in male HAB rats might be related to increased AVP signaling per se rather than to impaired corticosteroid feedback inhibition. However, it is more likely that the phenomena reported here are linked to changes in mechanisms other than those detected by measuring $B_{\max }$ and $K_{d}$, e.g. at the level of post-receptor signaling cascades (Holsboer 2000), including differences in the homo- or heterodimerization pattern of gluco- and mineralocorticoid receptors (Trapp et al. 1994) and their association with transcription factors and chaperones (Truss and Beato 1993). In support of this notion is the previous finding that in transgenic mice with impaired GR function, long-term treatment with the antidepressant moclobemide led to an increased GR function without changes in GR binding (Montkowski et al. 1995).

In summary, we could demonstrate that a high level of inborn emotionality is accompanied by impaired stress hormone regulation as reflected by an altered outcome of the DEX/CRH test. We submit that a basal hyperdrive of the hypothalamic vasopressinergic system contributes to this phenomenon. Thus, the increased release of endogenous AVP into hypophysial portal vessels is likely to mediate, together with the exogenous $\mathrm{CRH}$, the escape of ACTH and corticosterone from DEX-induced HPA suppression. These data provide additional evidence in support of the hypothesis that in patients suffering from major depression the intrahypothalamic AVP release is enhanced, contributing to both endocrine and psychopathological abnormalities (Müller et al. 2000a).

\section{ACKNOWLEDGMENTS}

The authors would like to thank M. Rücker, G. Kohl, A. Zahn, K. Moschke and P. Lörscher for expert technical assistance. 
The $\mathrm{V}_{1}$ receptor antagonist was kindly provided by Dr. M. Manning, Toledo, OH, USA. This work was supported by the Deutsche Forschungsgemeinschaft (DFG). I.D.N. is in receipt of a Heisenberg grant from the DFG.

\section{REFERENCES}

Antoni FA (1993): Vasopressinergic control of pituitary adrenocorticotropin secretion comes of age. Front Neuroendocrinol 14:76-122

Buwalda B, de Boer SF, Schmidt ED, Felszeghy K, Nyakas C, Sgoifo A, van der Vegt BJ, Tilders FJH, Bohus B, Koolhaas JM (1999): Long-lasting deficient dexamethasone suppression of hypothalamic-pituitary-adrenocortical activation following peripheral CRF challenge in socially defeated rats. J Neuroendocrinol 11:513-520

de Bellis MD, Gold PW, Geracioti TD Jr, Listwak SJ, Kling MA (1993): Association of fluoxetine treatment with reductions in CSF concentrations of corticotropinreleasing hormone and arginine vasopressin in patients with major depression. Am J Psychiatry 150:656-667

de Goeij DCE, Dijkstra H, Tilders FJH (1992): Stress-induced increases in vasopressin and corticotropin-releasing factor expression in hypophysiotrophic paraventricular neurons. Endocrinology 131:847-853

de Kloet ER, Vreugdenhil E, Oitzl MS, Joels M (1998): Brain corticosteroid receptor balance in health and disease. Endocr Rev 19:269-301

Gillies GE, Linton EA, Lowry PJ (1982): Corticotropin releasing activity of the new CRF is potentiated several times by vasopressin. Nature 299:355-357

Hatzinger M, Reul JMHM, Landgraf R, Holsboer F, Neumann I (1996): Combined dexamethasone/CRH test in rats: hypothalamo-pituitary-adrenocortical system alterations in aging. Neuroendocrinology 64:349-356

Hatzinger M, Wotjak CT, Naruo T, Simchen R, Keck ME, Landgraf R, Holsboer F, Neumann ID (2000): Endogenous vasopressin contributes to hypothalamic-pituitaryadrenocortical alterations in aged rats. J Endocrinol 164: 197-205

Henniger MSH, Ohl F, Hölter SM, Weissenbacher P, Toschi N, Lörscher P, Wigger A, Spanagel R, Landgraf R (2000): Unconditioned anxiety and social behaviour in two rat lines selectively bred for high and low anxietyrelated behaviour. Behav Brain Res 111:153-163

Heuser I, Bissette G, Dettling M, Schweiger U, Gotthardt U, Schmider J, Lammers CH, Nemeroff CB, Holsboer F (1998): Cerebrospinal fluid concentrations of corticotropin-releasing hormone, vasopressin, and somatostatin in depressed patients and healthy controls: response to amitriptyline treatment. Depression Anxiety 8:71-79

Heuser I, Yassouridis A, Holsboer F (1994): The combined dexamethasone/CRH test-a refined laboratory test for psychiatric disorders. J Psychiatr Res 28:341-356

Heuser IJE, Schweiger U, Gotthardt U, Schmider J, Lammers CH, Dettling M, Yassouridis A, Holsboer F (1996): Pituitary-adrenal-system regulation and psychopathology during amitriptyline treatment in elderly depressed patients and in normal comparison subjects. Am J Psychiatry 153:93-99
Holsboer F (1999): The rationale for corticotropin-releasing hormone receptor (CRH-R) antagonists to treat depression and anxiety. J Psychiatr Res 33:181-214

Holsboer F (2000): The corticosteroid receptor hypothesis of depression. Neuropsychopharmacology 23:477-501

Holsboer F, Barden N (1996): Antidepressants and hypothalamic-pituitary-adrenocortical regulation. Endocr Rev 17:187-205

Holsboer F, Lauer CJ, Schreiber W, Krieg JC (1995): Altered hypothalamic-pituitary-adrenocortical regulation in healthy subjects at high familial risk for affective disorders. Neuroendocrinology 62:340-347

Ivell R, Richter D (1984): Structure and comparison of the oxytocin and vasopressin genes from rat. Proc Natl Acad Sci USA 81:2006-2010

Keck ME, Hatzinger M, Wotjak CT, Holsboer F, Landgraf R, Neumann ID (2000): Ageing alters intrahypothalamic release patterns of vasopressin and oxytocin in rats. Eur J Neurosci 12:1487-1494

Keck ME, Holsboer F (2001): Hyperactivity of CRH neuronal circuits as a target for therapeutic interventions in affective disorders. Peptides 22:835-844

Keck ME, Welt T, Post A, Müller MB, Toschi N, Wigger A, Landgraf R, Holsboer F, Engelmann M (2001a): Neuroendocrine and behavioral effects of repetitive transcranial magnetic stimulation in a psychopathological animal model are suggestive of antidepressant-like effects. Neuropsychopharmacology 24:337-349

Keck ME, Welt T, Wigger A, Renner U, Engelmann M, Holsboer F, Landgraf R (2001b): The anxiolytic effect of the CRH1 receptor antagonist R121919 depends on innate emotionality in rats. Eur J Neurosci 13:373-380

Kiss JZ (1988): Dynamisms of chemoarchitecture in the hypothalamic paraventricular nucleus. Brain Res Bull 20:699-708

Kiss JZ, Martos J, Palkovits M (1991): Hypothalamic paraventricular nucleus: a quantitative analysis of cytoarchitectonic subdivisions in the rat. J Comp Neurol 313:563-573

Kitay JI (1961): Sex differences in adrenal cortical secretion in the rat. Endocrinology 68:818-824

Krieger DT (1979): Rhythms in CRF, ACTH, and corticosteroids. In Krieger DT (ed), Endocrine Rhythms. New York, Raven Press, pp 123-142

Landgraf R, Kubota M, Holsboer F, Wotjak CT (1995): Release of vasopressin and oxytocin within the brain and into blood: microdialysis and antisense targeting. In Saito T, Kurokawa K, Yoshida S (eds), Neurohypophysis: Recent Progress of Vasopressin and Oxytocin Research. Amsterdam, Elsevier, pp 243-256

Landgraf R, Wigger A, Holsboer F, Neumann ID (1999): Hyperreactive hypothalamo-pituitary-adrenocortical (HPA) axis in rats bred for high anxiety-related behavior. J Neuroendocrinol 11:405-407

Liebsch G, Linthorst ACE, Neumann ID, Reul JMHM, Holsboer F, Landgraf R (1998a): Behavioral, physiological, and neuroendocrine stress responses and differential sensitivity to diazepam in two Wistar rat lines selectively bred for high and low anxiety-related behavior. Neuropsychopharmacology 19:381-396

Liebsch G, Montkowski A, Holsboer F, Landgraf R (1998b): Behavioural profiles of two Wistar rat lines selectively 
bred for high or low anxiety-related behaviour. Behav Brain Res 94:301-310

Lightman SL, Young WS (1989): Lactation inhibits stressmediated secretion of corticosterone and oxytocin and hypothalamic accumulation of corticotropin-releasing factor and enkephalin messenger ribonucleic-acids. Endocrinology 124:2358-2364

Lucassen PJ, Ravid R, Gonatas NK, Swaab DF (1993): Activation of the human supraoptic and paraventricular nucleus neurons with aging and in Alzheimer's disease as judged from increasing size of the Golgi apparatus. Brain Res 632:105-113

Lucki I (1997): The forced swimming test as a model for core and component behavioral effects of antidepressant drugs. Behav Pharmacol 8:523-532

Meijer OC, de Lange ECM, Breimer DD, de Boer AG, Workel JO, de Kloet ER (1998): Penetration of dexamethasone into brain glucocorticoid targets is enhanced in mdr1A P-glycoprotein knockout mice. Endocrinology 139:1789-1793

Modell S, Lauer CJ, Schreiber W, Huber J, Krieg JC, Holsboer F (1998): Hormonal response pattern in the combined DEX-CRH test is stable over time in subjects at high familial risk for affective disorders. Neuropsychopharmacology 18:253-262

Modell S, Yassouridis A, Huber J, Holsboer F (1997): Corticosteroid receptor function is decreased in depressed patients. Neuroendocrinology 65:216-222

Montkowski A, Barden N, Wotjak C, Stec I, Ganster J, Meaney M, Engelmann M, Reul JMHM, Landgraf R, Holsboer F (1995): Long-term antidepressant treatment reduces behavioural deficits in transgenic mice with impaired glucocorticoid receptor function. J Neuroendocrinol 7:841-845

Müller MB, Landgraf R, Keck ME (2000a): Vasopressin, major depression, and hypothalamic-pituitary-adrenocortical desensitization. Biol Psychiatry 47:330-333

Müller MB, Landgraf R, Preil J, Sillaber I, Kresse AE, Keck ME, Zimmermann S, Holsboer F, Wurst W (2000b): Selective activation of the hypothalamic vasopressinergic system in mice deficient for the corticotropin-releasing hormone receptor 1 is dependent on glucocorticoids. Endocrinology 141:4262-4269

Neumann ID, Johnstone HA, Hatzinger M, Liebsch G, Shipston M, Russell JA, Landgraf R, Douglas AJ (1998a): Attenuated neuroendocrine responses to emotional and physical stressors in pregnant rats involve adenohypophysial changes. J Physiol 508:289-300

Neumann ID, Wigger A, Liebsch G, Holsboer F, Landgraf R (1998b): Increased basal activity of the hypothalamopituitary-adrenal axis during pregnancy in rats bred for high anxiety-related behaviour. Psychoneuroendocrinology 23:449-463

Neumann ID, Wigger A, Torner L, Holsboer F, Landgraf R (2000): Brain oxytocin inhibits basal and stress-induced activity of the hypothalamo-pituitary-adrenal axis in male and female rats: partial action within the paraventricular nucleus. J Neuroendocrinol 12:235-243

Neumann ID, Toschi N, Ohl F, Torner L, Krömer SA (2001): Maternal defence as an emotional stressor in female rats: correlation of neuroendocrine and behavioral parameters and involvement of brain oxytocin. Eur J Neurosci 13:1016-1024
Ohl F, Toschi N, Wigger A, Henniger MSH, Landgraf R (2001): Dimensions of emotionality in a rat model of innate anxiety. Behav Neurosci 115:429-436

Paxinos G, Watson C (1986): The Rat Brain in Stereotaxic Coordinates. Sydney, Academic Press.

Purba JS, Hoogendijk WJG, Hofman MA, Swaab DF (1996): Increased number of vasopressin- and oxytocinexpressing neurons in the paraventricular nucleus of the hypothalamus in depression. Arch Gen Psychiatry 53:137-143

Raadsheer FC, Sluiter AA, Ravid R, Tilders FJH, Swaab DF (1993): Localization of corticotropin-releasing hormone $(\mathrm{CRH})$ neurons in the paraventricular nucleus of the human hypothalamus: age-dependent colocalization with vasopressin. Brain Res 615:50-62

Reul JMHM, de Kloet ER (1985): Two receptor systems for corticosterone in rat brain: microdistribution and differential occupation. Endocrinology 117:1803-1812

Reul JMHM, Stec I, Soder M, Holsboer F (1993): Chronic treatment of rats with the antidepressant amitriptyline attenuates the activity of the hypothalamic-pituitaryadrenocortical system. Endocrinology 133:312-320

Rivier C (1999): Gender, sex steroids, corticotropin-releasing factor, nitric oxide, and the HPA response to stress. Pharmacol Biochem Behav 64:739-751

Rivier C, Brownstein M, Spiess J, Rivier J, Vale W (1982): In vivo corticotropin-releasing-factor-induced secretion of adrenocorticotropin, $\beta$-endorphin, and corticosterone. Endocrinology 110:272-278

Schinkel AH, Wagenaar E, van Deemter L, Mol CAAM, Borst P (1995): Absence of the mdr1a P-glycoprotein in mice affects tissue distribution and pharmacokinetics of dexamethasone, digoxin, and cyclosporin A. J Clin Invest 96:1698-1705

Tilders FJH, Schmidt ED, de Goeij DCE (1993): Phenotypic plasticity of CRF neurons during stress. Ann NY Acad Sci 697:39-52

Trapp T, Rupprecht R, Castren M, Reul JMHM, Holsboer F (1994): Heterodimerization between mineralocorticoid and glucocorticoid receptor - a new principle of glucocorticoid action in the CNS. Neuron 13:1457-1462

Truss M, Beato M (1993): Steroid-hormone receptors-interaction with deoxyribonucleic-acid and transcription factors. Endocr Rev 14:459-479

Vale W, Spiess J, Rivier C, Rivier J (1981): Characterization of a 41-residue ovine hypothalamic peptide that stimulates secretion of corticotropin and $\beta$-endorphin. Science 213:1394-1397

Viau V, Meaney MJ (1991): Variations in the hypothalamicpituitary-adrenal response to stress during the estrous cycle in the rat. Endocrinology 129:2503-2511

Villar MJ, Ceccatelli S, Ronnqvist M, Hökfelt T (1994): Nitric oxide synthase increases in hypothalamic magnocellular neurons after salt loading in the rat. An immunohistochemical and in situ hybridization study. Brain Res 644:273-281

von Bardeleben U, Holsboer F (1985): Combined administration of corticotropin-releasing factor and lysine vasopressin induces cortisol escape from dexamethasone suppression in healthy subjects. Life Sci 37:1613-1618 
Walker CD (1995): Chemical sympathectomy and maternal separation affect neonatal stress responses and adrenal sensitivity to ACTH. Am J Physiol 268:1281-1288

Weinstock M (1997): Does prenatal stress impair coping and regulation of hypothalamic-pituitary-adrenal axis? Neurosci Biobehav Rev 21:1-10

Wigger A, Neumann ID (1999): Periodic maternal deprivation induces gender-dependent alterations in behavioral and neuroendocrine responses to emotional stress in adult rats. Physiol Behav 66:293-302

Wotjak CT, Kubota M, Kohl G, Landgraf R (1996a): Release of vasopressin from supraoptic neurons within the rat median eminence in vivo. A combined microdialysis and push-pull perfusion study in the rat. Brain Res 726:237-241
Wotjak CT, Kubota M, Liebsch G, Montkowski A, Holsboer F, Neumann I, Landgraf R (1996b): Release of vasopressin within the rat paraventricular nucleus in response to emotional stress: a novel mechanism of regulating adrenocorticotropic hormone secretion? J Neurosci 16:7725-7732

Zobel AW, Nickel T, Sonntag A, Uhr M, Holsboer F, Ising M (2001): Cortisol response in the combined dexamethasone/CRH test as predictor of relapse in patients with remitted depression: a prospective study. J Psychiatr Res 35:83-94

Zobel AW, Yassouridis A, Frieboes RM, Holsboer F (1999): Prediction of medium-term outcome by cortisol response to the combined dexamethasone-CRH test in patients with remitted depression. Am J Psychiatry 156:949-951 